\title{
Simultaneous spectrophotometric determination of phosphate and silicate in different water and soil samples using chemometrics approach
}

\author{
M. A. Tarighat ${ }^{1}$
}

Received: 18 December 2014/Revised: 14 April 2015/Accepted: 2 June 2015/Published online: 2 July 2015

(C) Islamic Azad University (IAU) 2015

\begin{abstract}
Continuous wavelet transform together with zero-crossing technique was applied to the overlapping visible spectra, as a very simple and accurate method, for the simultaneous determination of phosphate and silicate without any prior separation steps. Daubechies-4, Symlet 8, and Meyer continuous wavelet transforms for signal treatments were found to be suitable. The calibration graphs for estimation of complexes were obtained by measuring the wavelet coefficients at zero-crossing points for silicomolybdenum blue and phosphomolybdenum blue. The constructed calibration functions were tested by analyzing the composition of the different binary mixtures. The experimental data were also analyzed using partial least squares and first-order derivative spectrophotometric method. The proposed method was validated by simultaneous determination of phosphate and silicate in different environmental waters and soil samples. The results of proposed method have been compared with those predicted by partial least squares and standard methods.
\end{abstract}

Keywords Continuous wavelet transformation . Derivative method · Partial least squares $\cdot$ Seawater

\section{Introduction}

Wavelet is a word which means a 'small wave'. Wavelet transforms (WT) are based on small wavelets with limited duration. One of the main features of WT is that it may

M. A. Tarighat

matarighat@gmail.com

1 Department of Chemistry, Faculty of Sciences, Persian Gulf University, 75169 Bushehr, Iran decompose a signal directly according to the frequency and represent its frequency domain distribution state in the time domain. In the transformation, both time and frequency information of the signal are retained. Hence, the translated-version wavelets locate where we concern, and the scaled-version wavelets allow us to analyze the signal in different scale. In chemical studies, the time domain can be replaced by other domains such as wavelength. Wavelet theory can be divided into four main categories which include: continuous wavelet transform (CWT), discrete wavelet transforms, orthonormal bases of wavelets, and redundant discrete systems (frames).

The CWT is a continuous convolution of the wavelet function with the signal over the entire continuum of wavelet scales. The combined use of CWT and zero-crossing technique has been applied for the quantitative resolution of various binary and ternary mixtures (Dinc and Baleanu 2003a, b, 2004, 2006; Olgun et al. 2013; Gupta et al. 2014; Sohrabi and Zarkesh 2014; Yola et al. 2014, 2015).

Recently, combination of ratio spectra and CWT for the simultaneous determination of $\mathrm{Ca}^{2+}, \mathrm{Mg}^{2+}$, and $\mathrm{Zn}^{2+}$ (Afkhami et al. 2008a) and $\mathrm{Co}^{2+}, \mathrm{Ni}^{2+}$, and $\mathrm{Cu}^{2+}$ (AbbasiTarighat and Afkhami 2012) in different milk, pharmaceutical, and vegetal samples has been reported. Also, determination of enantiomeric composition of $\alpha$-phenylglycine using UV spectra of cyclodextrin host-guest complexes, prior to neural network construction, was performed using CWT (Afkhami et al. 2008b).

As the continuation of Abbasi Tarighat et al. works, the applicability of wavelet transformation was examined to the resolution of kinetic profiles of binary systems, and therefore the simultaneous determination of mixtures by kinetic data (Afkhami and Abbasi Tarighat 2009).

Also, simultaneous determination of $\mathrm{Cu}^{2+}$ and $\mathrm{Pb}^{2+}$ ions in various binary mixtures of red beans, walnut, rice, 
tea, and soil samples using CWT based on the complex formation with 2-benzyl espiro[iso indoline-1,5oxasolidine]-2,3,4 trione was successfully reported (Abbasi Tarighat et al. 2015).

Phosphate and silicate ions are nutrients which have effects on the growth of different macro- and microorganisms such as plants, algae, and phytoplankton diatoms (Harper 1992) and build rigid diatom frustules. A high loading of nutrients such as phosphate ion from watershed to semi-closed water area such as lake and estuary eventually leads to algae growth, resulting in a bloom which is a very abundant dense growth of algae. Also, the silica deficiency in freshwater was caused by the accumulation of diatom frustules in bottom sediment, leading to a changing of phytoplankton species composition in the coastal seawater (Nakatania et al. 2008). Therefore, the monitoring of nutrients such as phosphate and silicate ions in water is important for controlling and evaluating the water quality and investigation of biogeochemical cycles of nutrients.

Direct determination of phosphate and silicate by spectrophotometric methods due to mutual interference between them is very difficult. The problem has serious consequences in view of the widespread utilization of phosphate and silicate in synthetic detergents, water softeners, surfactants, some alloys, and many other applications. Masking agent and $\mathrm{pH}$ controlling (Chalmers and Sincair 1966), sequential injection analysis (Torres et al. 1997), flow-through cell by using fluorophotometric detection (Oshima et al. 1996), and flow injection analysis (Meaney et al. 2002) were used for the simultaneous determination of phosphate and silicate. Application of flow analysis for determination purpose requires careful control of experimental conditions. Therefore, this can become important disadvantage for determination in analytical chemistry that should be considered. In the latest years, first-derivative spectrophotometric method (ElSayed et al. 2001) and ion exclusion chromatography techniques with conductivity detection ( $\mathrm{Li}$ and Chen 2000) have been proposed for their simultaneous quantifications. An unwanted effect of the derivative methods is the decrease in $S / N$.

Recently, neural networks were developed for the simultaneous determination of phosphate and silicate in detergent samples. Artificial neural networks need several set of data as calibration, prediction, and validation sets. Also like as multiplicative calibration methods, all of component should be presented in calibration step. Also, designing architect of ANNs is a time-consuming process and is not easy to perform (Afkhami and Abbasi Tarighat 2008).
As mentioned before, classic spectrophotometric methods have been used for determination of phosphate and silicate in different samples. However, conventional spectrophotometric methods yield poor results for quantitative analysis of multi-component mixtures due to overlapping absorption spectra in the same spectral region. Therefore, the representation of a signal by means of its spectrum or Fourier transform is essential for solving mentioned problems in different science(Nounou and Nounou 2010; Rajaee et al. 2010; Jalalkamali et al. 2015).

This study explains method of achieving time-dependent frequency analysis method (e.g., CWT). The main advantage of CWT in extraction of characteristic information of highly overlapped signals because of its good temporal localization properties and fast calculations was applied. Hence, CWT method based on the use of zero-crossing technique was developed for the simultaneous determination of phosphate and silicate in the presence of several unknown interfering components without any separation steps. After identification of the optimal wavelet families, providing the best prediction ability, the applicability of method for quantitative determination of phosphate and silicate was examined in different samples. The results showed that the quality of the obtained results was not a function of overlapped spectra. For the comparison purpose, partial least square (PLS) calibration and first-order derivative spectrophotometric methods were applied to predict the content of the same mixtures containing the subject active compounds. Analysis of the results for binary mixtures with CWT showed that the use of CWT models for absorbance data provides the high prediction ability with respect to PLS and first-derivative spectrophotometric methods. Therefore, the proposed method was successfully applied to the simultaneous determination of phosphate and silicate ions in seawater, river water, mineral water, wastewater, pond, irrigation canals, and soil samples. The results of proposed method were compared by those obtained on the same samples by reference methods.

\section{Mathematical tool}

\section{Wavelet transform basic}

Basically, for short-time Fourier transforms (STFT), WT is a means of obtaining a representation of both time and frequency contents of a signal. But in WT the window function width is dependent on the central frequency (Mallat 1999). Therefore, for a given analysis function, the best trade-off between time and frequency resolutions can be automatically obtained. The CWT of a continuous signal $x(t)$ is given by: 
$W_{a, b}(x)=\int_{-\infty}^{+\infty} x(t) \psi_{(a, b)}^{*}(t) \mathrm{d} t$

with the wavelet function defined by dilating and translating $a$ "mother" function as:

$\psi_{(a, b)}(t)=\frac{1}{\sqrt{a}} \psi\left(\frac{t-b}{a}\right)$

where $\psi(t)$ being the "mother" wavelet, $a$ is the dilation factor, and $b$ is the translation parameter (both being real positive numbers). Selection of an appropriate wavelet filter may be guided by empirical rules applied to data size and signal continuity. The typical way is to visually inspect the data first and select an appropriate wavelet filter (Afkhami et al. 2008b).

In addition to wavelet function, dilation has also an important role to get maximum resolution and sensitivity. A proper dilation was selected using the introduced criterion by Xiaoquan et al. (2004).

fitness $(c)=\sum_{b=1}^{\text {length } f(x)}\left[\left|W f_{(c)}(b)\right|-|f(b)|\right]^{2}$

fitness $(c)$ represents the cumulated difference between the wavelet coefficients $W f_{(a)}(b)$ and the original data at each transition. CWT analysis was performed as following steps:

Step 1 Place the wavelet at the beginning of the signal and set $a=1$ (the most compressed wavelet);

Step 2 The wavelet function at scale " 1 " is multiplied by the signal, integrated over all times, and then multiplied by $\frac{1}{\sqrt{a}}$;

Step 3 Shift the wavelet to $t=b$ and get the transform value at $t=b$ and $a=1$;

Step 4 Repeat the procedure until the wavelet reaches the end of the signal;

Step 5 Scale s is increased by a sufficiently small value, and the above procedure is repeated for all $a$;

Step 6 Each computation for a given $a$ fills the single row of the timescale plane;

Step $7 \mathrm{CWT}$ is obtained if all $\mathrm{s}$ are calculated.

The dilation which makes the fitness $(c)$ have the minimum value would be chosen as the best dilation. For binary mixtures of A and B, by transformation of calibration set of two analytes, their calibration functions are obtained. The signal at zero-crossing point of the transformed signal corresponding to one component belongs to the signal of the second ones. Hence, prediction of concentration of each analyte in binary mixture was estimated by substitution of measured CWT signal in calibration equations at zerocrossing points of another analyte.

\section{Materials and methods}

\section{Reagents}

Chemicals were purchased from Sigma-Aldrich and Merck (Darmstadt, Germany) and used as-received with no further purification. A stock solution of phosphate (100.0 $\mathrm{mg} \mathrm{mL}^{-1}$ ) was prepared by dissolving potassium dihydrogen phosphate in 100.0-mL volumetric flask. Stock solutions of silicate $\left(50.0 \mathrm{mg} \mathrm{mL}^{-1}\right)$ and sodium molybdate solution $\left(0.02 \mathrm{~mol} \mathrm{~L}^{-1}\right)$ was prepared by appropriate dilution of sodium silicate solution and $\left(\mathrm{NH}_{4}\right)_{6}$ $\mathrm{Mo}_{7} \mathrm{O}_{24} \cdot 2 \mathrm{H}_{2} \mathrm{O}$ with water, respectively. Ascorbic acid, $3 \times 10^{-2} \mathrm{~mol} \mathrm{~L}^{-1}$, was prepared by dissolving appropriate amount of ascorbic acid in $100.0 \mathrm{~mL}$ of distilled water.

\section{Spectra and data analysis}

A model 713 Metrohm pH meter using a combined glass electrode was used for the $\mathrm{pH}$ measurement of solutions. A detection system consisting of an Analytical Jena SPECORD250-22P16 UV-Vis double-beam spectrophotometer using 1-cm quartz cells, slit of $0.5 \mathrm{~cm}$, and scan speed of $100 \mathrm{~nm} \mathrm{~s}^{-1}$ was selected. The recorded spectra were digitized with one data point per nanometer. All calculations were performed by MATLAB (version 7.1, MathWorks, Natik, MA, USA).

\section{Procedure}

Two sets of standard solutions containing the two anions were prepared as calibration and prediction sets. The correlation between concentrations of the two anions was avoided. Appropriate amounts of phosphate and silicate and $1.0 \mathrm{~mL}$ molybdate solution were added to a $10-\mathrm{mL}$ volumetric flask and allowed to stand for $15 \mathrm{~min}$. Then $1 \mathrm{~mL}$ ascorbic acid was added and heated for $3 \mathrm{~min}$ at $50{ }^{\circ} \mathrm{C}$. The solution was cooled and made up to the mark with water and allowed to stand at room temperature for $5 \mathrm{~min}$. A portion of the solution was transferred into a $1-\mathrm{cm}$ quartz cell to record the absorbance spectra against a blank solution in the wavelength range $500-950 \mathrm{~nm}$ with $1-\mathrm{nm}$ intervals.

\section{Results and discussion}

\section{Absorption spectra}

Figure 1a shows spectral data in the range 500-950 nm for aqueous solutions of silicomolybdenum blue, phosphomolybdenum blue complexes, and their mixture. This 


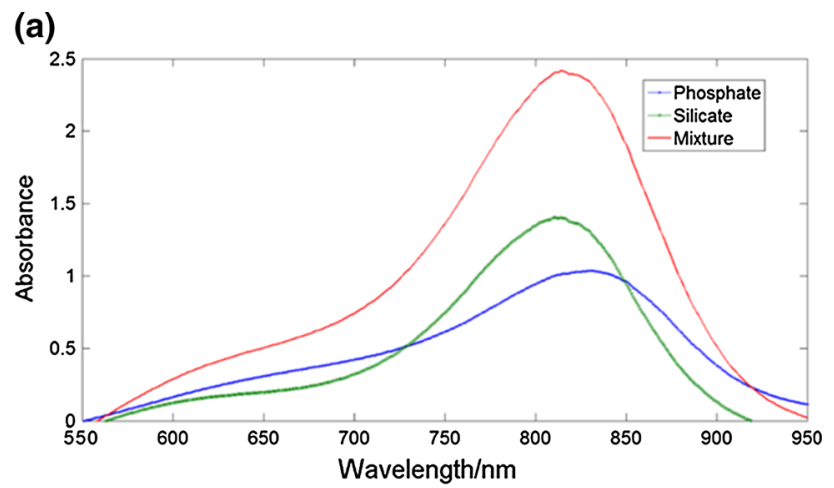

(b)

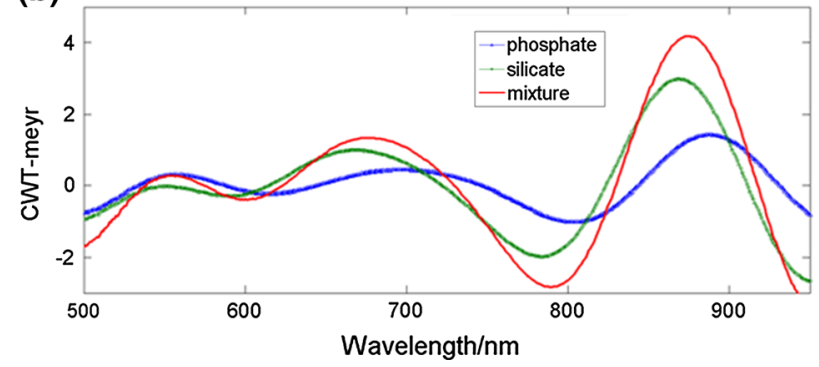

Fig. 1 a Absorption spectra for (1) $2.0 \mathrm{mg} \mathrm{L}^{-1}$ and (2) $2.0 \mathrm{mg} \mathrm{L}^{-1}$ phosphate and their mixture. b CWT spectra of species, in the presence of $0.02 \mathrm{~mol} \mathrm{~L}^{-1}$ ammonium molybdate and $3.0 \times 10^{-2}$. mol $\mathrm{L}^{-1}$ ascorbic acid

figure illustrates significant spectral overlap in the system. Therefore, species will create interference effect in the spectrophotometric determination of each other. Hence, to their mutual interference, the simultaneous determination of phosphate and silicate in the same samples is not possible by using the classical analytical methodologies. To solve the above-mentioned problems, CWT was developed and was successfully applied for the first time for the simultaneous determination of phosphate and silicate at different real mixtures (Fig. 1b).

\section{Optimization of the reaction conditions}

For simultaneous determination of ions, the optimum working conditions were obtained as follow: $0.05 \mathrm{~mol} \mathrm{~L}^{-1}$ sulfuric acid $(1.50 \mathrm{~mL})$, molybdate $0.02 \mathrm{~mol} \mathrm{~L}^{-1}$ $(1.0 \mathrm{~mL})$, and $3 \times 10^{-2} \mathrm{~mol} \mathrm{~L}^{-1}(1.0 \mathrm{~mL})$ ascorbic acid.

\section{Selection of appropriate mother wavelets and analytical parameters}

The absorption spectra of the standard solutions of phosphate and silicate with different concentrations were recorded in the wavelength range 500-950 $\mathrm{nm}$ (Fig. 2). The recorded spectra were transferred from EXCEL to MATLAB 7.1 domain.

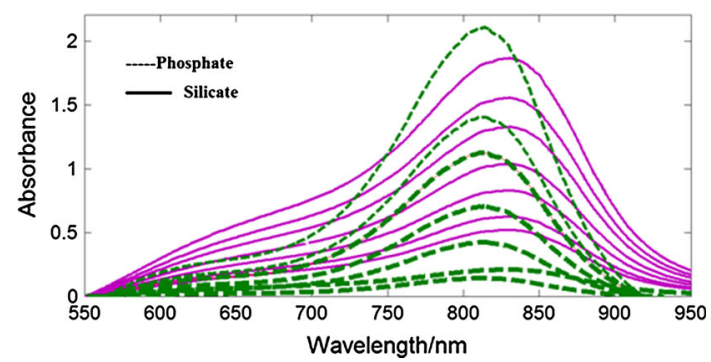

Fig. 2 Absorption spectra for phosphate (a) and silicate (b) in the calibration range of $0.10-3.0 \mathrm{mg} \mathrm{L}^{-1}$

As mentioned before, type of mother wavelet and decomposition level should be optimized.

There is no absolute way to choose a certain wavelet. The choice of wavelet depends upon the type of signal to be analyzed and the application. There are several wavelet families like Haar, Daubechies, Biorthogonal, Coiflets, Symlets, Morlet, Mexican Hat, Meyer. The Daubechies and Meyer wavelets are family of orthogonal wavelets. The most known family of orthonormal wavelets is the family of Daubechies. These wavelets characterized by maximal number of vanishing moments for some given support and usually are denominated by the number of nonzero coefficients. However, Daubechies-4 (db4) wavelet has been found to give details more accurately than others. In general the Daubechies wavelets are chosen to have the highest number $A$ of vanishing moments, for given support width $N=2 A$. There are two naming schemes in use, $\mathrm{D} N$ using the length or number of taps, and $\mathrm{db} A$ referring to the number of vanishing moments. In applied mathematics, Symlet wavelets are a family of wavelets. They are modified version of Daubechies wavelets with increased symmetry (Daubechies 1988).

For the best compression and smoothing of spectra, the degree of similarity between the original data and transformed spectra should be pointed (see the theory of wavelet transform). The best mother wavelet is a function that can create distinct zero-crossing points for components. Therefore, Daubechies-4 (db4), Symlet 8 (sym8), and Meyer (meyr) were selected and used. Transformation was carried out in the optimum dilations, 60, 80, and 110 for $\mathrm{db} 8$, sym8, and meyr, respectively. Figure 3 shows the graphs of CWT-db8 coefficients of phosphate and silicate at $a=60$. According to the previous reports of author, the best scaling value was obtained by using Eq. 3. In present study, the same procedure was applied. For more clarity of the selection criteria, the analysis by $\mathrm{db} 8$ was performed at different dilations. The results of dilation values are presents in Table 1 . As Table 1 shows, the sensitivity $R^{2}$ and linear dynamic range LOD (Miller and Miller 2005) values 


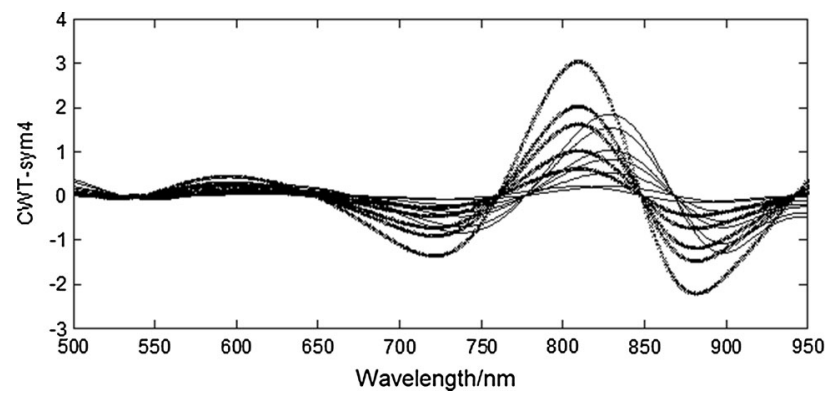

Fig. 3 CWT-db8 graphs of phosphate $(-)$ and silicate $(x)$ in the calibration ranges

of CWT-db8 at $a=70$ were higher than other dilation values (at $a=40$ and $a=100$ ). The results showed that at low dilation values, several zero-crossing points were created where intensity of signals were decreased. This occasion resulted in the reduction in sensitivity of determination. In presence of large dilation values, the intensity of signals will be increased, whereas interference effect at simultaneous determination will be enhanced due to more closeness of zero-crossing points. Hence, the accuracy and precision of simultaneous determination of phosphate and silicate due to interference effects will be decreased.

As Table 2 and Fig. 3 show, CWT-db8 signals of silicate have several zero-crossing points which can be used for determination of phosphate in binary mixtures. The best zero-crossing points were selected based on maximum sensitivity and minimum overlapping. Hence, calibration equations for phosphate were obtained by measuring the CWT-db8 signals of phosphate at zero-crossing points for silicate. Similarly, a calibration equation for silicate was obtained by measuring the CWT-db8 signals of silicate at zero-crossing points for phosphate. Linear regression analysis and its statistical results are shown in Table 2.

As the result shows, a good linearity with the good correlation coefficients was observed using db8 (see Table 2). Hence, the validation of CWT-db8 approach was performed by using an independent set of the synthetic mixtures containing phosphate and silicate (prediction set). The contents of phosphate and silicate in binary synthetic mixtures were determined with calibration equations in zero-crossing points. Mean results and their relative standard deviation (for three determinations) were obtained using by CWT-db8 approach and are presented in Table 3 . The LOD and LOQ were calculated by using the standard deviation of slopes of the linear regression equations which is presented in Table 2 .

Also, calibration graphs for phosphate at zero-crossing points of silicate and graphs of silicate at zero-crossing points of phosphate were obtained using by meyr and sym 4 (see Fig. 4). Linear regression analysis and its statistical results, LOD and LOQ, are shown in Tables 4 and 5. The mean recovery values and standard deviations (std) are given Table 3. Comparing the outputs of proposed mother wavelets for the simultaneous determination of phosphate
Table 1 Statistical results of calibration graphs obtained at zero-crossing points using CWT-db8 at different dilation values

Table 2 Statistical results of calibration graphs obtained at zero-crossing points using CWT-db8

\begin{tabular}{lcclll}
\hline Anion & Dilation value & $\lambda / \mathrm{nm}$ & Regression equation & Linear range & $R^{2}$ \\
\hline Phosphate & 40 & 558 & $A=0.0202 C_{P}+0.001$ & $0.2-3.0$ & 0.989 \\
& 70 & 567 & $A=0.069 C_{P}+0.016$ & $0.1-3.0$ & 0.998 \\
& 100 & 570 & $A=0.0391 C_{P}+0.002$ & $0.1-2.2$ & 0.992 \\
Silicate & 40 & 571 & $A=-0.015 C_{\mathrm{Si}}-0.008$ & $0.4-2.2$ & 0.996 \\
& 70 & 580 & $A=-0.285 C_{\mathrm{Si}}-0.102$ & $0.4-2.5$ & 0.962 \\
& 100 & 58 & $A=-0.015 C_{\mathrm{Si}}-0.008$ & $0.4-2.8$ & 0.998 \\
\hline
\end{tabular}

\begin{tabular}{|c|c|c|c|c|c|c|}
\hline Anion & $\lambda / \mathrm{nm}$ & Regression equation & Linear range & $R^{2}$ & $\mathrm{LOD} / \mathrm{mg} \mathrm{L}^{-1}$ & $\mathrm{LOQ} / \mathrm{mg} \mathrm{L}^{-1}$ \\
\hline \multirow[t]{6}{*}{ Phosphate } & 559 & $A=0.069 C_{P}+0.016$ & $0.08-3.0$ & 0.989 & \multirow[t]{6}{*}{0.021} & \multirow[t]{6}{*}{0.085} \\
\hline & 628 & $A=-0.027 C_{P}-0.006$ & $0.08-3.0$ & 0.998 & & \\
\hline & 688 & $A=0.023 C_{P}-0.005$ & $0.08-3.0$ & 0.991 & & \\
\hline & 723 & $A=-0.007 C_{P}-0.001$ & $0.08-3.0$ & 0.991 & & \\
\hline & 755 & $A=0.010 C_{P}+0.002$ & $0.08-3.0$ & 0.998 & & \\
\hline & 838 & $A=-0.062 C_{P}-0.015$ & $0.08-3.0$ & 0.991 & & \\
\hline \multirow[t]{5}{*}{ Silicate } & 571 & $A=-0.056 C_{\mathrm{Si}}-0.013$ & $0.4-2.8$ & 0.991 & \multirow[t]{5}{*}{0.03} & \multirow[t]{5}{*}{0.29} \\
\hline & 640 & $A=0.310 C_{\mathrm{Si}}+0.008$ & $0.4-2.5$ & 0.991 & & \\
\hline & 713 & $A=-0.009 C_{\mathrm{Si}}-0.001$ & $0.4-2.8$ & 0.998 & & \\
\hline & 768 & $A=-0.016 C_{\mathrm{Si}}-0.002$ & $0.4-2.8$ & 0.991 & & \\
\hline & 860 & $A=0.328 C_{\mathrm{Si}}+0.410$ & $0.4-2.8$ & 0.991 & & \\
\hline
\end{tabular}


Table 3 Mean recovery values and standard deviations (std) obtained by different mother wavelets and PLS- 1 to different binary mixture of phosphate and silicate

\begin{tabular}{lrllll}
\hline Method & Phosphate & Silicate & \multicolumn{1}{l}{$t_{\text {crit }}^{\mathrm{a}}$} & \multirow{2}{*}{$t_{\text {cal }}$} \\
\cline { 4 - 5 } & & & Phosphate & Silicate & \\
\hline $\mathrm{db} 8$ & $99.67 \pm 1.53$ & $101.07 \pm 1.79$ & 1.39 & 1.13 & \multirow{2}{*}{4.30} \\
sym4 & $100.67 \pm 2.08$ & $100.83 \pm 1.61$ & 1.24 & 1.65 & \\
meyr & $101.23 \pm 1.97$ & $102.17 \pm 0.58$ & 0.75 & 1.20 & \\
PLS & $101.53 \pm 2.27$ & $102.17 \pm 2.08$ & & & \\
\hline
\end{tabular}

a $P=0.05$
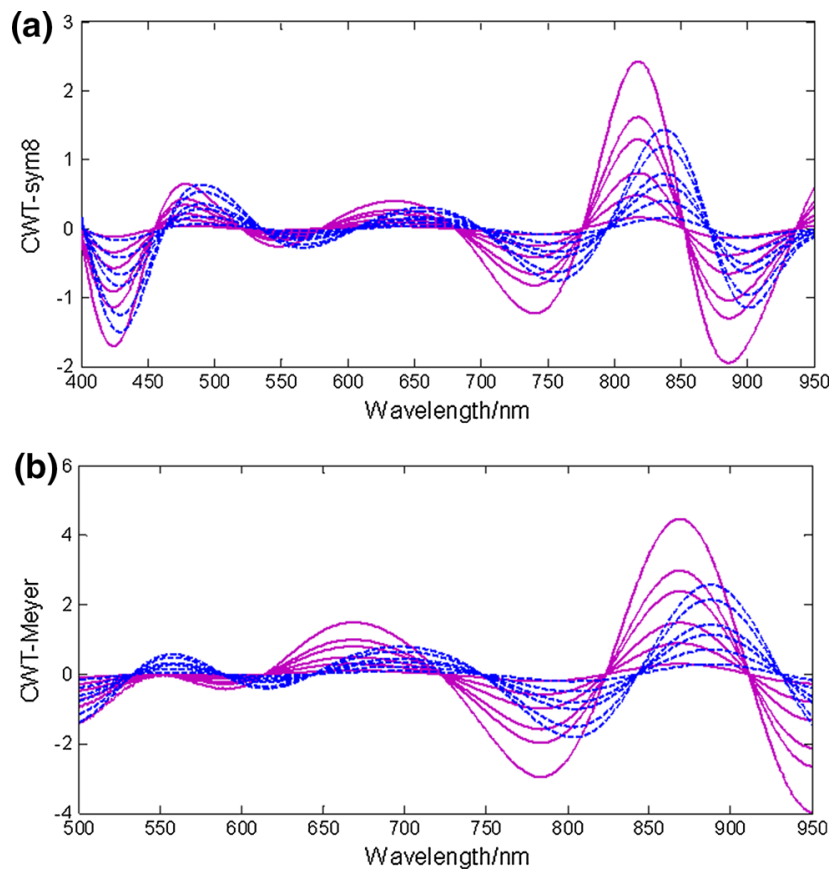

Fig. 4 a CWT-Sym8 graphs of phosphate (dash line) and silicate (solid line) in calibration ranges. b The CWT-meyer graphs of phosphate (dash line) and silicate (solid line) in calibration ranges

and silicate with each other showed that there is high level of agreement between obtained results. Hence, CWT can be applied as a powerful approach for the simultaneous determination of ions.
The prediction error of a single component in the mixtures calculated as the relative standard error (R. S. E.) for the prediction concentration was calculated according:

R.S.E $=\left(\frac{\sum_{i=1}^{N}\left(\hat{C}_{i j}-C_{i j}\right)^{2}}{\sum_{i=1}^{N}\left(C_{i j}\right)^{2}}\right)^{0.5} \times 100$

where $N$ is the number of samples, $C_{i j}$ the concentration of the component in the $j$ th mixture, and $\hat{C}_{i j}$ is the estimated concentration. The total prediction error (R. S. E.) of N samples is estimated. The reasonable single R. S. E. was 1.98 and $1.80 \%$, for phosphate and silicate, respectively.

In order to validate the proposed method, the experimental data were also analyzed using partial least squares (PLS-1) algorithm. PLS-1 can be also used to resolve of spectral overlapping, but the error of prediction results will be increased by increasing the correlation of components. PLS-1 factors were optimized. The number of latent variables (factors) for each ion was determined by the crossvalidation method leaving out one sample at a time (Madrakian et al. 2007). The prediction error sum of squares (PRESS) for cross-validated models was calculated. The best model was selected with four latent factors which accounted for $95.0 \%$ of the variance (Fig. 5). The mean recoveries and standard deviations were calculated and are presented at Table 3. Also, the R. S. E values were calculated as 2.9 and $2.6 \%$ for phosphate and silicate, respectively. The results obtained by the proposed method
Table 4 Statistical results of calibration graphs obtained at zero-crossing points using CWT-sym4

\begin{tabular}{|c|c|c|c|c|c|c|}
\hline Anion & $\lambda / \mathrm{nm}$ & Regression equation & Linear range & $R^{2}$ & $\mathrm{LOD} / \mathrm{mg} \mathrm{L}^{-1}$ & $\mathrm{LOQ} / \mathrm{mg} \mathrm{L}^{-1}$ \\
\hline \multirow[t]{4}{*}{ Phosphate } & 554 & $A=-0.045 C_{P}-0.016$ & $0.08-3.0$ & 0.995 & \multirow[t]{4}{*}{0.024} & \multirow[t]{4}{*}{0.079} \\
\hline & 648 & $A=-0.081 C_{P}-0.021$ & $0.08-3.0$ & 0.991 & & \\
\hline & 762 & $A=0.228 C_{P}-0.085$ & $0.08-3.0$ & 0.995 & & \\
\hline & 848 & $A=0.575 C_{\mathrm{P}}+0.216$ & $0.08-3.0$ & 0.995 & & \\
\hline \multirow[t]{5}{*}{ Silicate } & 528 & $A=-0.027 C_{\mathrm{Si}}-0.003$ & $0.2-2.8$ & 0.991 & \multirow[t]{5}{*}{0.03} & \multirow[t]{5}{*}{0.10} \\
\hline & 582 & $A=0.037 C_{\mathrm{Si}}+0.017$ & $0.4-2.5$ & 0.991 & & \\
\hline & 673 & $A=-0.170 C_{\mathrm{Si}}-0.021$ & $0.4-2.8$ & 0.998 & & \\
\hline & 779 & $A=0.515 C_{\mathrm{Si}}+0.064$ & $0.4-2.8$ & 0.991 & & \\
\hline & 869 & $A=-0.653 C_{\mathrm{Si}}-0.082$ & $0.4-2.8$ & 0.991 & & \\
\hline
\end{tabular}


Table 5 Statistical results of calibration graphs obtained at zero-crossing points using CWT-meyr

\begin{tabular}{lllllll}
\hline Anion & $\lambda / \mathrm{nm}$ & Regression equation & Linear range & $R^{2}$ & $\mathrm{LOD} / \mathrm{mg} \mathrm{L}^{-1}$ & $\mathrm{LOQ} / \mathrm{mg} \mathrm{L}^{-1}$ \\
\hline Phosphate & 619 & $A=-0.182 C_{P}-0.046$ & $0.08-3.0$ & 0.998 & 0.021 & 0.085 \\
& 725 & $A=0.255 C_{P}-0.065$ & $0.08-3.0$ & 0.991 & & \\
Silicate & 525 & $A=-0.428 C_{P}-0.147$ & $0.08-3.0$ & 0.998 & & \\
& 537 & $A=-0.027 C_{\mathrm{Si}}-0.003$ & $0.4-2.8$ & 0.998 & 0.03 & 0.029 \\
& 640 & $A=0.037 C_{\mathrm{Si}}+0.017$ & $0.4-2.8$ & 0.998 & & \\
& 768 & $A=-0.170 C_{\mathrm{Si}}-0.021$ & $0.4-2.8$ & 0.991 & & \\
& 845 & $A=0.40 C_{\mathrm{Si}}+0.052$ & $0.4-2.8$ & 0.998 & & \\
\hline
\end{tabular}

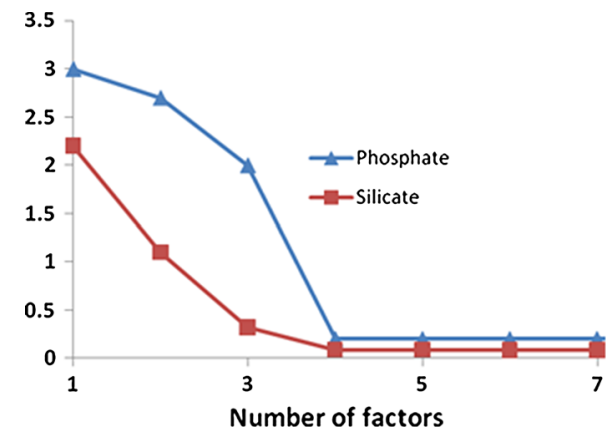

Fig. 5 Plot of PRESS against the number of factors for phosphate and silicate

were compared with those obtained by PLS-1 method using student's $t$ test. The results are given in Table 3 . As the results show, the calculated $t$-values for phosphate and silicate by CWT are less than the tabulated values. This indicates that there is no difference between the obtained values by the proposed method and PLS-1. Also, due to lower R. S. E. values, the performance of CWT method is higher compared with that of the PLS-1 method.

We can simply conclude that selection of zero-crossing point in CWT domain, rather than spectra domain in PLS-1 model, not only effectively eliminates background interference and noise but also further reduces the number of variables (coefficients) required for a good calibration resulting in a high-quality regression model.

The CWT results and first-derivative spectrophotometric results (FDS) were compared with each other. First derivative of the absorption spectra of phosphate and silicate and their samples was calculated by using the interval of $\Delta \lambda=2 \mathrm{~nm}$ (Fig. 6). As this figure shows, derivative spectra of components are noisy, there are no clear and distinct zero-crossing points, and intensity of created spectra was low. Therefore, for simultaneous determination of phosphate and silicate, due to low sensitivity and highinterference exciting, derivative spectrophotometry for
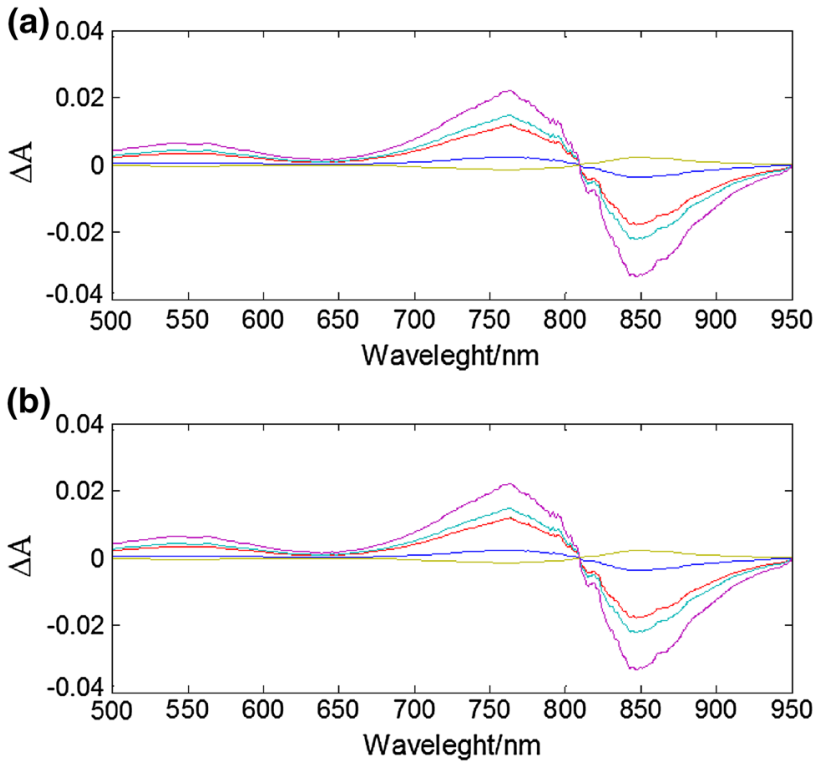

Fig. 6 The Smoothed first spectra with $\Delta \lambda=7 \mathrm{~nm}$ of (a) phosphate and (b) silicate in the calibration range

further analysis was rejected. As the CWT graphs and numerical results indicate, the accuracy and precision of the results obtained by CWT were higher than those obtained by the FDS method.

\section{Interference effect}

In order to investigate the selectivity of the proposed method, the effects of foreign species on the simultaneous determination of phosphate and silicate were investigated. The common existing interferences of species were investigated to test the selectivity, as well as the influence of some other surface-active compounds. The tolerance limit was taken as the maximum concentration of foreign species that caused a relative error of approximately $\leq 5 \%$ for the determination of $0.8 \mathrm{mg} \mathrm{L}^{-1}$ of phosphate and 
silicate plus the potential interfering substances. The results are shown in Table 6. As Table 6 shows, many of cations and anions did not interfere in phosphate and silicate determination. The interfering effect of $\mathrm{AsO}_{4}{ }^{3-}$ can be removed up to 2.3 and 2.5 for phosphate and silicate, respectively, by addition of $1 \mathrm{~mL}$ of $15 \%$ sodium thiosulfate.

Table 6 Effect of foreign ions on the simultaneous determination of phosphate and silicate $\left(0.8 \mathrm{mg} \mathrm{L}^{-1}\right.$ each of phosphate and silicate)

\begin{tabular}{lll}
\hline Foreign ion & \multicolumn{2}{l}{ Tolerance limit/mg L } \\
\cline { 2 - 3 } & Phosphate & Silicate \\
\hline $\mathrm{Na}^{+}, \mathrm{K}^{+}$ & $>1000$ & $>1500$ \\
$\mathrm{Al}^{3+}, \mathrm{Ag}^{+}$ & 500 & $>700$ \\
$\mathrm{Cr}_{2} \mathrm{O}_{7}^{2-}, \mathrm{Mg}^{2+}$ & 500 & 850 \\
$\mathrm{Co}^{2+}, \mathrm{Cd}^{2+}, \mathrm{Cu}^{2+}, \mathrm{Pb}^{2+}$ & 1000 & 1000 \\
$\mathrm{Ni}^{2+}, \mathrm{Mn}^{2+}$ & 1000 & 800 \\
$\mathrm{Fe}^{2+}, \mathrm{Fe}^{3+}$ & 300 & $>600$ \\
$\mathrm{Cl}^{-1}, \mathrm{CO}_{3}{ }^{2-}$ & $>1000$ & $>1000$ \\
$\mathrm{I}^{-}, \mathrm{F}^{-}, \mathrm{SO}_{4}{ }^{2-}$ & 500 & 500 \\
$\mathrm{Hg}^{2+}, \mathrm{NO}_{3}{ }^{-}$ & 1000 & 1000 \\
$\mathrm{CN}^{-}, \mathrm{MnO}_{4}{ }^{-}, \mathrm{SCN}^{-}$ & 600 & 650 \\
$\mathrm{Sn}^{2+}, \mathrm{Zn}^{2+}$ & 10 & 15 \\
$\mathrm{AsO}_{4}{ }^{3-}$ & 2.3 & 2.5 \\
\hline
\end{tabular}

\section{Applications}

The methods were tested by their application to the simultaneous determination of phosphate and silicate in different water and soil samples (Table 7). Reference methods were used for determination of phosphate and silicate at different samples (American Public Health Association 1995). Comparison of the results obtained by the proposed method with those obtained by standard method confirmed the accuracy of the results obtained by CWT approach. Also, the results show that there is no significant difference between the obtained results of mother wavelets. Therefore, the proposed method can be applied as a precise and accurate method for determination of the phosphate and silicate ions in a wide variety of water samples.

\section{Conclusion}

The applicability of the proposed procedure for the analysis of real samples with different matrices was assessed by its application to the simultaneous determination of phosphate and silicate ions in various real samples. This method was the first reported for the simultaneous determination of phosphate and silicate using transformed signals. There is a good agreement between results obtained by this method and results obtained by standard methods. The predicted

Table 7 Predicted amount of phosphate and silicate in different water and soil samples using different mother wavelets

\begin{tabular}{|c|c|c|c|c|c|c|c|c|}
\hline \multirow[t]{3}{*}{ Sample } & \multicolumn{8}{|l|}{ Wavelet } \\
\hline & \multicolumn{2}{|l|}{ CWT-db8 } & \multicolumn{2}{|l|}{ CWT-sym4 } & \multicolumn{2}{|l|}{ CWT-meyr } & \multicolumn{2}{|c|}{ Reference method } \\
\hline & Phosphate & Silicate & Phosphate & Silicate & Phosphate & Silicate & Phosphate & Silicate \\
\hline Seawater ${ }^{1, a}$ & 0.032 & 0.38 & 0.032 & 0.392 & 0.038 & 0.39 & $0.038 \pm 0.013$ & $0.396 \pm 0.02$ \\
\hline Seawater ${ }^{2, a}$ & 0.035 & 0.416 & 0.038 & 0.416 & 0.041 & 0.42 & $0.042 \pm 0.010$ & $0.416 \pm 0.02$ \\
\hline Seawater ${ }^{3, a}$ & 0.022 & 2.12 & 0.028 & 2.18 & 0.027 & 2.24 & $0.028 \pm 0.012$ & $2.22 \pm 1.85$ \\
\hline River water ${ }^{\text {b }}$ & 0.0244 & 2.201 & 0.0256 & 2.202 & 0.0254 & 2.32 & $0.025 \pm 0.018$ & $2.32 \pm 0.07$ \\
\hline Mineral water & 0.621 & 1.64 & 0.628 & 1.72 & 0.631 & 1.72 & $0.636 \pm 0.024$ & $1.68 \pm 0.01$ \\
\hline Wastewater ${ }^{1, \mathrm{~b}}$ & 0.562 & 2.82 & 0.568 & 2.84 & 0.568 & 2.64 & $0.564 \pm 0.015$ & $2.90 \pm 0.02$ \\
\hline Wastewater ${ }^{2, b}$ & 0.623 & 2.78 & 0.628 & 2.79 & 0.631 & 2.79 & $0.630 \pm 0.022$ & $2.82 \pm 0.018$ \\
\hline Pond $^{\mathrm{c}}$ & $\mathrm{ND}^{\mathrm{d}}$ & 0.55 & ND & 0.553 & $\mathrm{ND}$ & 0.56 & $0.021 \pm 0.002$ & $0.62 \pm 0.02$ \\
\hline Irrigation canals ${ }^{\mathrm{b}}$ & ND & 3.12 & ND & 3.22 & ND & 3.12 & $0.016 \pm 0.004$ & $3.28 \pm 0.014$ \\
\hline Soil $^{\mathrm{e}}$ & 0.742 & 2.30 & 0.790 & 2.36 & 2.38 & 0.76 & $0.742 \pm 0.02$ & $2.33 \pm 0.01$ \\
\hline Soill $^{\mathrm{e}}$ & 0.252 & 4.10 & 0.282 & 4.22 & 0.252 & 4.16 & $0.28 \pm 0.02$ & $4.2 \pm 0.01$ \\
\hline
\end{tabular}

${ }^{a}$ Determined without dilution

b Determined with five times dilution

c Determined with 10 times dilution

${ }^{\mathrm{d}}$ Not detected

e Sample $(0-15 \mathrm{~cm})$ collected from soil

Seawater: ${ }^{1}$ Bandargah Station-Bushehr Port, ${ }^{2}$ Delavar Station-Delvar, ${ }^{3}$ Genaveh Station-Genaveh

Wastewater: ${ }^{1}$ Wastewater lift station Busheher, ${ }^{2}$ Wastewater lift station Deylam 
values obtained by application of the CWT model for absorbance data show the high prediction ability of the CWT method with respect to PLS and first-order derivative spectrophotometric method. CWT approach applied to the absorption spectra provided higher peak amplitudes, fewer noises, and sharp peaks. Therefore, proposed method provides a good reproducibility and gives a precise, rapid, highly sensitive and selective procedure with good LODs and lower R. S. E values. Also, the algorithm of CWT is very simple and very fast for learning. Therefore, its application becomes simpler for researchers in the analytical applications. In case of PLS algorithm, we believe that their applications need basic and advanced mathematical background. Also, in some cases, these preparations of calibration set and prediction set get unsolvable problems for mathematical treatments due to the lack of inverse of some involved matrices. Hence, the CWT curves can be used instead of other calibration models for simultaneous determination of phosphate and silicate.

Acknowledgments The authors wish to thank all who assisted in preparation of this work

\section{References}

Abbasi Tarighat M, Nabavi M, Mohammdizadeh MR (2015) Chemometrics-assisted spectrophotometric method for simultaneous determination of $\mathrm{Pb}^{2+}$ and $\mathrm{Cu}^{2+}$ ions in different foodstuffs, soil and water samples using 2-benzylspiro [isoindoline-1,5'-oxazolidine]-2',3,4'-trione using continuous wavelet transformation-calculation of $\mathrm{pK}_{\mathrm{f}}$ of complexes with rank annihilation factor analysis. Spectrochim Acta 145:54-62

Abbasi-Tarighat M, Afkhami A (2012) Simultaneous spectrophotometric determination of $\mathrm{Cu}$ (II), $\mathrm{Co}$ (II) and $\mathrm{Ni}$ (II) using ratio spectra-continuous wavelet transformation in some food and environmental samples. J Braz Chem Soc 23:1312-1319

Afkhami A, Abbasi Tarighat M (2008) Comparative determination of phosphate and silicate using molybdenum blue by radial basis function and feed-forward neural networks assisted by principal component analysis. Anal Sci 24:779-783

Afkhami A, Abbasi Tarighat M (2009) Application of continuous wavelet transformation to the simultaneous kinetic determination of binary mixtures. Talanta 78:424-431

Afkhami A, Madrakian T, Abbasi-Tarighat M (2008a) Simultaneous determination of calcium, magnesium and zinc in different foodstuffs and pharmaceutical samples with continuous wavelet transforms. Food Chem 109:660-669

Afkhami A, Abbasi-Tarighat M, Bahram M (2008b) Artificial neural networks for determination of enantiomeric composition of alpha-phenylglycine using UV spectra of cyclodextrin host-guest complexes: comparison of feed-forward and radial basis function networks. Talanta 75:91-98

American Public Health Association (1995) Standard methods for the examination of water and waste water, 19th edn. Water Environment Federation, American Water-work Association, Denver

Chalmers RA, Sincair AG (1966) Analytical applications of $\beta$ heteropoly acids: this influlsnce of complexing agents on selective formation. Anal Chim Acta 34:412-418
Daubechies I (1988) Orthonormal bases of compactly supported wavelets. Commun Pure Appl Math 41:909-996

Dinc E, Baleanu D (2003a) Multidetermination of thiamine HC1 and pyridoxine $\mathrm{HC} 1$ in their mixture using continuous daubechies and biorthogonal wavelet analysis. Talanta 59:707-717

Dinc E, Baleanu D (2003b) A zero-crossing technique for the multidetermination of thiamine $\mathrm{HCl}$ and pyridoxine $\mathrm{HCl}$ in their mixture by using one-dimensional wavelet transform. J Pharm Biomed Anal 31:969-978

Dinc E, Baleanu D (2004) Application of the wavelet method for the simultaneous quantitative determination of benazepril and hydrochlorothiazide in their mixtures. J AOAC Int 87:834-841

Dinc E, Baleanu D (2006) Wavelet transform and artificial neutral network for the quantitative resolution of ternary mixtures. Rev Chim 57:626-631

El-Sayed AY, Hussein YZ, Mohammed MA (2001) Simultaneous determination of phosphate and silicate in detergents and waters by first-derivative spectrophotometry. Analyst 126:1810-1815

Gupta VK, Yola ML, Atar N (2014) A novel molecular imprinted nanosensor based quartz crystal microbalance for determination of kaempferol. Sens Actuator B Chem 194(2014):79-85

Harper D (1992) Eutrophication of fresh waters: principles problems and restoration. Chapman and Hall, London, p 336

Jalalkamali A, Moradi M, Moradi N (2015) Application of several artificial intelligence models and ARIMAX model for forecasting drought using the Standardized Precipitation Index. Int $\mathrm{J}$ Environ Sci Technol 12:1201-1210

Li HB, Chen F (2000) Determination of silicate in water by ion exclusion chromatography with conductivity detection. J Chromatogr A 874:143-147

Madrakian T, Afkhami A, Moein R, Bahram M (2007) Simultaneous spectrophotometric determination of Sn (II) and Sn (IV) by mean centering of ratio kinetic profiles and partial least squares methods. Talanta 72:1847-1852

Mallat S (1999) A wavelet tour of signal processing. Academic Press, London

Meaney AJL, Ellis PS, Worsfold PJ, Butler ECV, McKelvie ID (2002) A compact flow injection analysis system for surface mapping of phosphate in marine waters original. Talanta 58:1043-1053

Miller JC, Miller JN (2005) Statistics and chemometrics for analytical chemistry, 5th edn. Pearson Education, London, pp 121-122

Nakatania N, Kozakia D, Masuda W, Nakagoshia N, Hasebe K (2008) Simultaneous spectrophotometric determination of phosphate and silicate ions in river water by using ion-exclusion chromatographic separation and post-column derivatization. Anal Chim Acta 619:110-115

Nounou MN, Nounou HN (2010) Multiscale estimation of the Freundlich adsorption isotherm. Int J Environ Sci Te 7:509-518

Olgun A, Atar N, Wang S (2013) Batch and column studies of phosphate and nitrate adsorption on waste solids containing boron impurity. Chem Eng J 222:108-119

Oshima M, Goto N, Susanto S, Motomizu S (1996) Determination of phosphate as aggregates of ion associates by light-scattering detection and application to flow injection. Analyst 121:1085-1088

Rajaee T, Mirbagheri SA, Nourani V, Alikhani A (2010) Prediction of daily suspended sediment load using wavelet and neurofuzzy combined model. Int J Environ Sci Te 7:93-110

Sohrabi MahshidMR, Zarkesh T (2014) Spectra resolution for simultaneous spectrophotometric determination of lamivudine and zidovudine components in pharmaceutical formulation of human immunodeficiency virus drug based on using continuous wavelet transform and derivative transform techniques. Talanta 122:223-228 
Torres F, Munoz A, Estela JM, Cerda V (1997) Simultaneous determination of phosphate and silicate in waste water by sequential injection analysis. Analyst 122:1033-1038

Xiaoquan L, Hongde L, Zhonghua X, Qiang Z (2004) Maximum spectrum of continuous wavelet transform and its application in resolving an overlapped signal. J Chem Inf Comput Sci 44:1228-1237
Yola ML, Eren T, İlkimen H, Atar N, Yenikay C (2014) A sensitive voltammetric sensor for determination of $\mathrm{Cd}$ (II) in human plasma. J Mol Liq 197:58-64

Yola ML, Eren T, Atar N (2015) A sensitive molecular imprinted electrochemical sensor based on gold nanoparticles decorated grapheme oxide: application to selective determination of tyrosine in milk. Sens Actuator B Chem 210:149-157 